\title{
Protecting the vulnerable victim in criminal injuries matters
}

\author{
Robert Guthrie \\ Office of Criminal Injuries Compensation, Perth WA 6841, Australia. robert.guthrie@justice.wa.gov.au
}

Each year large numbers of persons sustain serious injury as a consequence of criminal behaviours. All Australian jurisdictions provide systems of compensation to those harmed in this way. In many instances assessors of compensation have to consider not simply the appropriate and fair amount of compensation but how a person will be affected by the payment of compensation. Often those applicants apply through their guardians or a public trustee, although many applicants apply in person. This paper examines the use of legislative provisions, rules regulations and practices in the various Australian jurisdictions in relation to how vulnerable criminal injuries applicants may be protected once an award of compensation is made in their favour. Most jurisdictions provide for a mechanism by which compensation awarded may be held in trust in the event that the compensation assessor considers that the applicant may be unable to manage her or his financial affairs and where it would be in the best interests of the applicant. When considering what is in the best interests of the applicant the assessor will have regard to the manner in which the inability to manage financial matters has arisen either as a consequence of the offence the subject of the application, pre-exiting mental health issues, substance addiction and abuse or vulnerability to exploitation by family members or close associates. This paper explores what factors are taken into account by assessors in the absence of and pursuant to legislative directions. It considers how the approach may vary across jurisdictions and creative approaches to protection vulnerable criminally injured persons. 